\title{
AS ONTOLOGIAS DO COMUM E A PSICOLOGIA SOCIAL: FRAGMENTOS DE UMA APOSTA
}

\author{
LAS ONTOLOGÍAS DEL COMÚN Y LA PSICOLOGÍA SOCIAL: \\ FRAGMENTOS DE UNA APUESTA
}

\author{
THE ONTOLOGIES OF THE COMMON AND SOCIAL PSYCHOLOGY: \\ FRAGMENTS OF A BET
}

\author{
Clara Urzedo Rocha Motta ${ }^{1}$ e Danichi Hausen Mizoguchi ${ }^{1}$ \\ ${ }^{1}$ Universidade Federal Fluminense, Niterói/RJ, Brasil
}

\begin{abstract}
RESUMO: No presente artigo, pretende-se apresentar as bases ontológicas que possibilitam a emergência de um modo específico de performatizar a Psicologia Social a partir daquilo que denominaremos de ontologias do comum. Ao versarmos sobre a ontologia, o fazemos considerando-a um modo de montar o mundo, sempre revestido de uma dimensão ética, estética e política. É a partir dessa indissociabilidade entre ontologia e ética que nos afastamos da tradição filosófica da representação e nos aproximamos principalmente da perspectiva de Baruch de Espinosa e Friedrich Nietzsche - notadamente junto ao modo como os filósofos franceses Gilles Deleuze e Michel Foucault singularizam as respectivas apropriações destes pensadores. Sob este trabalho de revisão bibliográfica é que, a partir de um mosaico conceitual, gostaríamos de entender alguns conceitos-ferramenta como fundamentais para pensarmos a teoria e a prática de uma Psicologia Social específica na qual apostamos.

PALAVRAS-CHAVE: Filosofia; Psicologia Social; Ética.
\end{abstract}

RESUMEN: En el presente artículo, se pretende presentar las bases ontológicas que posibilitan la emergencia de un modo específico de performatizar la Psicología Social a partir de lo que denominaremos de ontologías de lo común. Al versar sobre la ontología, lo hacemos considerando un modo de montar el mundo, siempre revestido de una dimensión ética, estética y política. Es a partir de esa indisociación entre ontología y ética que nos alejamos de la tradición filosófica de la representación y nos acercamos principalmente a la perspectiva de Baruch de Espinosa y Friedrich Nietzsche, sobre todo al modo en que los filósofos franceses Gilles Deleuze y Michel Foucault singularizan la apropiación de estos pensadores. En este trabajo de revisión bibliográfica es que, a partir de un mosaico conceptual, quisiéramos entender algunos conceptos-herramienta como fundamentales para pensar la teoría y la práctica de una Psicología Social específica en la que apostamos.

PALABRAS CLAVE: Filosofía; Psicología Social; Ética.

ABSTRACT: In this article, we intend to present the ontological foundations that enable the emergence of a specific mode of Social Psychology which we refer to as the common ontologies. When we talk about ontology, we consider it to be a way of assembling the world, always coated with an ethical, aesthetics and politics dimension. It is from this inseparability between ontology and ethics that we move away from the philosophical tradition of representation and we come mainly from the perspective of Baruch Spinoza and Friedrich Nietzsche - notably along the way as the French philosophers Gilles Deleuze and Michel Foucault singularize the work of these thinkers. Under this work of literature review, from a conceptual mosaic, we would like to understand some concepts-tool as essential to think about the theory and practice of a specific Social Psychology in which we bet.

KEYWORDS: Philosophy; Social Psychology; Ethic. 


\section{Introdução: passagens de uma aposta de campo}

O presente artigo coloca-se sob uma empreitada de campo: é como uma aposta atinente à Psicologia Social que ele efetiva seu empuxo, sua pertinência e sua peculiaridade. Trata-se de um movimento e de um problema, portanto, implicados às tensões, às divergências e às modulações que montaram a história e as arenas de um campo disperso e disputado em que se encontram pensadores tão díspares quanto Wilhelm Wundt, Gustave Le Bon, George Herbert Mead, Floyd Allport, Gordon Allport, Kurt Lewin e Silvia Lane.

Nesse sentido, fazemos eco à indicação feita por Mary Jane e Peter Spink no tex to "A Psicologia Social na atualidade", quando afirmam que "há intensas disputas, pouca tolerância sobre pontos de vista diferentes e nenhuma concordância sobre quais seriam os pressupostos teóricos básicos" (Spink \& Spink, 2005, p. 565) no trajeto histórico da Psicologia Social. São, portanto, várias atualidades deste campo específico, assim como da psicologia de um modo geral, conforme indica Georges Canguilhem (1973) em seu tex to canônico "O que é a Psicologia?". Adentrar neste campo disperso e disputado, incidindo nele aspectos que nos parecem interessantes e pouco utilizados é nossa intenção neste artigo.

Todavia, a despeito das interrogações e das apostas específicas de campo que caracterizam o texto, ele somente pode fazer-se em encontro com algo aquém e além desta suposta interioridade disciplinar. Aquilo que conduz o texto é a seara filosófica onde se encontram e desencontram as tentativas de defesa de um certo modo de montar o mundo: a ontologia. Nesta amplitude de discussão, tentar-se-á forjar as bases - mesmo que por demais superficiais e amplas, incipientes, necessariamente fragmentadas - de uma ficção de mundo apta a dar passagem a um estilo peculiar de performatizar a Psicologia Social junto àquilo que doravante chamaremos - amparados notadamente em Baruch de Espinosa e Friedrich Nietzsche - de uma ontologia do comum.

Por fim, ainda na introdução do presente artigo, é imperioso que se coloque um breve alerta: sabe-se que não há novidade naquilo que é convocado nesta escrita. Tantos e tantos pesquisadores da Psicologia já insinuaram as coligações entre os fragmentos que doravante esboçarão nossa aposta. Não é, pois, em busca de um ineditismo que estaremos: mais e menos do que isso, nosso tônus de escrita se dá por crermos interessante compreendermos e sustentarmos uma aposta que em nós é simultaneamente frágil e forte e com ela buscarmos uma rede de conspiração.

Ademais, a proposta de tornar público o presente artigo surge também da quase ausência de referências no Brasil que deem passagem a uma Psicologia Social que considere abordagens baseadas nas concepções espinosista e nietzschianas, bem como das constantes interrogações acerca da legitimidade destes autores no campo científico e acadêmico da Psicologia. Se é verdade que há trabalhos que passam próximos dos autores centrais em nossa argumentação - como, por exemplo, o livro de Laurent Bove, Espinosa e a Psicologia Social (2010), também é verdade que esses trabalhos são raros. Entendemos que essa perspectiva teórica diz respeito a conceituações que modificam legitimamente a própria psicologia social, com aspectos que não são contemplados pelas perspectivas tradicionalmente abordadas na história deste campo, o que justifica a escrita e a publicização deste artigo.

Além disso, essa estirpe de conceituação é muitas vezes colocada sob a perspectiva crítica latino-americana ou sob a vertente daquilo que Robert Farr (2013) chamou de psicologia social sociológica, o que nos parece um equívoco. Se é verdade que a entonação 
que propomos encontra algumas aproximações com as críticas fundamentais realizadas junto à crise da Psicologia Social nos anos 1970, materializadas com consistência por Martín-Baró (2017), é também preciso dizer que não se restringe a elas, e em alguns momentos difere fortemente de suas direções. Sabemos bem, conforme indicam Simone Maria Hüning e Andrea Cristina Coelho Scisleski, que dar "nome ao que pensamos e fazemos impõe riscos" (2018, p. 9). Ainda assim, seguindo o que indicam as autoras, defendemos atribuir um nome a um modo de pensar em Psicologia Social, "não o fazemos para sufocar o pensamento a uma classificação, mas para demarcar um posicionamento ético-político" (Hüning \& Scileski, 2018, p. 9) que certamente "visa a arejar novas rotas, novas práticas, novos modos de resistir, recusar e desobedecer em Psicologia social” (Hüning \& Scileski, 2018, p. 9), fazendo parte dessa história que, por sua característica ausência de unidade, é aqui chamada de tortuosa.

\section{Ontologia e criação: entre o mundo e os conceitos}

É recorrente, na tradição filosófica, a submissão da ontologia a certo caráter unívoco. Se uma certa fundação da filosofia ocidental e do modo de pensar e viver espraiado a partir da Europa encontra um ponto de partida junto à tríade formada por Sócrates, Platão e Aristóteles, é interessante que se compreendam as extrações que dali incidem, desde cedo e até hoje, nas relações entre a verdade e a ontologia, porque talvez seja justamente ali que encontremos a estreia daquilo que estabelece as relações entre a verdade e o mundo as quais dão à ontologia um caráter unissonante e estático do qual gostaríamos, no presente artigo, de nos afastar.

No primeiro curso que ministrou no Collège de France, no começo da década de 1970, Michel Foucault defende a tese de que foi Aristóteles quem operou a histórica exclusão sofística (Foucault, 2014, p. 30). Se a exatidão de tal exclusão é de difícil demarcação, é certo que foi o estagirita quem chamou a sofística de uma filosofia aparente e sem realidade. É preciso que se depreenda com veemência que se os adversários da filosofia que Aristóteles fundava são aqueles próximos da aparência e distantes da realidade, é justamente porque a filosofia por ele defendida é o exato oposto: a distância da aparência e o pleno encaixe com a realidade.

É assim que, ao menos desde Aristóteles, a filosofia tem como tarefa fundamental a implicação basal entre duas verdades: a verdade das palavras e a verdade das coisas. Foucault diz com clareza na aula do dia 6 de janeiro de 1971: "enunciando o princípio das coisas, os filósofos enunciam o Ser propriamente dito. Portanto, pode-se dizer que a verdade é realmente a causa material da filosofia. Os princípios nela enunciados são, por si mesmos, aquilo que tem mais ser e aquilo que tem mais verdade" (Foucault, 2014, p. 31). Se há diferenças e divergências entre as enunciações filosóficas, o motivo não pode ser outro que não o equívoco dos filósofos, mas jamais da filosofia, porque, de fato, há uma "margem de acaso, de cegueira e de silêncio" (Foucault, 2014, p. 32) que cerca todo ato concreto de filosofar que pode os conduzir não a divergências e diferenças, mas aos erros. Ainda mais: se há diferenças ou divergências entre filósofos, é necessariamente porque há equívoco há um filósofo que não filosofa corretamente, não encontrando a verdade do ser das coisas.

Desde então, pensar a natureza do ser das coisas passa a ser visto como a efetivação de uma base sólida na qual se estabelece uma verdade maiúscula e existente em si mesma. 
Esta axiomática, o ponto de partida com o qual se desenvolve aquilo tudo que experimentamos e pactuamos chamar de mundo, passa a funcionar como um juízo de realidade. Sob esta direção, eis a tarefa da filosofia: efetivar o liame ontológico, preciso, único e natural entre as palavras e as coisas.

A racionalidade filosófica, portanto, aloca-se em posição supostamente privilegiada por sua capacidade de driblar os tropeços e ilusões mundanas em busca da verdade cristalina e unívoca. Em outros termos, é tarefa da filosofia dizer o ser do mundo, e isto só é possível, evidentemente, sob a crença de que há um ser do mundo, cuja descoberta e enunciação tornam-se as tarefas de um ramo da filosofia chamado ontologia. Se há um mundo que é, é tarefa do filósofo descobri-lo e representá-lo, enunciando uma e tão somente uma ontologia possível: enunciar, enfim, o mundo que é.

Todavia, a ontologia que protagoniza o título do presente artigo, cuja defesa nos parece importante para a defesa da Psicologia Social que nos toca, intenta desviar desta tradição filosófica representativa que implica palavras e coisas em uma relação unívoca. Longe de um fetiche criativo ou emancipatório, essa radicalidade é necessária, pois sem ela não seria possível o enlace dos conceitos constituintes da defesa ontológica que aqui quer se fazer.

Para a constituição de uma ontologia do comum é impreterível a retirada desse aspecto transcendente da verdade e a transposição desta para o trânsito das relações. A partir dessa nova direção, há a possibilidade de construções múltiplas acerca das relações características do problema ontológico: o mundo e a verdade, as palavras e as coisas, a filosofia e a existência. A relação entre estes termos deixa de derivar e ser pré-determinada pelos mesmos para fazer prevalecer um carácter coafetivo. Em outros termos, o ser das coisas adquire o viés da invenção e da multiplicidade: a ontologia aproxima-se estranhamente da ficção.

A verdade torna-se, portanto, fruto de construção, arranjo, engendramento: trata-se da entrada de certo aspecto contingencial e singular nesse novo campo de constituição. Se pensarmos em consonância com essas reflexões críticas acerca da verdade, torna-se desinteressante persistir com o problema ontológico representativo. É o anúncio de uma nova maneira de se pensar a ontologia e, consequentemente, a tarefa daquele que, literalmente, a cria: um estranho e paradoxal ser das coisas que não se funda necessariamente na garantia de que as coisas sejam. Segundo Silva (2004, p. 13), observa-se a importância dessa virada ontológica para Psicologia Social: "seria preciso antes de mais nada abandonar uma compreensão ingênua do social que, segundo Ibañez (1994), encontra-se ancorada em dois tipos de crenças mutuamente implicadas: a primeira consiste em crer na existência de uma realidade completamente independente de nosso modo de acesso a ela; a segunda, em crer que há um tipo de acesso privilegiado que nos conduziria, graças a uma busca constante de objetividade, à realidade tal como ela verdadeiramente existiria."

Há de se pensar nos motivos da insistência em uma afirmação da ontologia, se a verdade e a existência são tratadas aqui como artifícios. De fato, poderíamos colocar em questão a estratégia de defesa argumentativa, apontando para uma teorização que deixe de lado essa nomenclatura, dada a complicação que sua pompa e peso históricos induzem. Porém, não se pretende com o presente artigo criar um substituto para a ontologia, mas retirar dela seu caráter representativo: é ali onde a ontologia fraqueja que ela pode adquirir toda uma nova potência de invenção de verdades e de mundos (Zourabichvili, 2016). 
Percebe-se que este novo arranjo ontológico toma de assalto o aspecto transcendente e essencialista da existência: o real torna-se ficção e a filosofia torna-se aquela cuja tarefa é a criação de novos artifícios constituintes da materialidade do mundo. Se invertermos o primado aristotélico e pensarmos a tarefa primeira da filosofia como a criação de conceitos, conforme defendem Deleuze e Guattari (1992, p. 37), o filósofo torna-se um inventor de mundos: cabe a ele o ato de nomeação singular do real.

É isto que aqui nos interessa em nosso problema que se coloca sob o campo da Psicologia Social: trazer a ética e a estética a uma proximidade quase indistinguível da ontologia. Se a relação entre verdade e mundo obedece agora a esse novo paradigma, é preciso pensar o que se é a partir dos agenciamentos, ou seja, instaurar uma lógica existencial conectiva que pensa a ontologia pelas suas modulações ininterruptas: em última instância, dir-se-ia que o interesse implícito no traçado de uma ontologia do comum é pôr na vida essa radicalidade ética.

Problema de artifício, portanto. Problema ético, problema estético, problema político. Dito de outro modo, problema ontológico que não se desimplica de um caráter ficcional, ético, estético e político. Se Deleuze tem razão ao afirmar que o "presente envenenado do platonismo foi ter introduzido a transcendência em filosofia, ter dado à transcendência um sentido filosófico plausível” (Deleuze, 1997, p. 155), talvez se possa dizer que qualquer reação "contra o platonismo é um restabelecimento da imanência em sua extensão e em sua pureza, que proíbe o retorno de um transcendente” (Deleuze, 1997, p. 155). É assim que, junto com Deleuze, podemos e queremos dizer que "só escapam ao platonismo as filosofias da imanência pura: dos estóicos a Spinoza e Nietzsche” (Deleuze, 1997, p. 155) - e é com os dois últimos que vamos doravante.

Mas é importante lembrar que nos colocamos uma tarefa de campo: a montagem de um mundo ou de uma ontologia que seja a condição de possibilidade para uma Psicologia Social específica. E é notadamente com a intercessão de Espinosa e Nietzsche que os próximos passos serão dados: a busca ontológica que permita ao campo o escape de um caráter essencialista e transcendente - ou, em outros termos, a possibilidade de um campo absolutamente efetivado sob o primado daquilo que finalmente poderemos chamar de comum.

\section{Espinosa: da univocidade do ser à prática de alegria}

A centralidade de nossa primeira aposta - a indissociabilidade entre ontologia, estética e ética - ganha espessura a partir de traçados teóricos inscritos sob o solo epistêmico da modernidade. Todavia, pode-se dizer que trabalharemos, nesse próximo movimento do artigo, com autores que, cronologicamente localizados no alvorecer e no poente da modernidade, se fizeram ambos eticamente compromissados com um tempo por vir: Baruch de Espinosa e Friedrich Nietzsche.

Importante salientar novamente a arena posta para este combate ontológico: o esforço de contrapor as noções e práticas de Psicologia Social - majoritariamente norte-americanas, mas não somente elas - que, de modo geral, pensam o indivíduo e a sociedade de maneira dicotômica, restringindo as possibilidades de atuação do psicólogo nesta área a análises de influência comportamentais e cognitivas à relação entre um indivíduo e um 
grupo. Dizemos respeito, portanto, a este esforço ético-político de um pensamento que não se encontra descolado de um mundo e de uma prática: a essa ontologia encarnada que se reconhece como máquina de produção de mundos e, portanto, se distancia dos legados da tradição majoritária da Psicologia Social.

De acordo com Frederico Alves Costa e Marco Aurélio Máximo Prado (2016), até a chamada crise da Psicologia Social, "nas décadas de 1970 e 1980, diferentes teóricos questionaram o modelo de Psicologia Social dominante, majoritariamente desenvolvido nos Estados Unidos" (Costa \& Prado, 2016, p. 217), que se apresentava como "base a Psicologia Social behaviorista experimental, e que a partir, sobretudo, da década de 1960, instituiu-se como uma psicologia social cognitiva experimental" (Costa \& Prado, 2016, p. 217 ) - fazendo com que Psicologia Social e Psicologia Social Cognitiva fossem quase sinônimos.

Segundo Ana Maria Jacó-Vilela, Filipe Degani-Carneiro e Dayse de Marie Oliveira (2016) e Gonçalves e Portugal (2016), esta vertente, cujas características marcantes são individualismo, experimentalismo, microteorização, etnocentrismo, utilitarismo, cognitivismo e a-historicismo, é a que chega ao Brasil. Muitas vezes, tais características são apontadas como sendo da própria psicologia social, o que indica a supremacia hegemonia dessa corrente. A influência crescente do modelo estadunidense de universidade, buscado pela intelectualidade brasileira desde os anos de 1930, forjou a predominância de um caráter de neutralidade e afastamento da realidade social na formação dos novos psicólogos.

Esse modo cindido de compreensão da complexa relação entre indivíduo e sociedade na história da psicologia social nos convida a um mergulho naquele que consideramos um dos conceitos-chave da obra de Espinosa: a imanência. Imanência como conceito-ferramenta de transgressão de fronteiras; imanência como o desdobrar que retorna à vida naquilo em que ela é pura e simplesmente vida.

De acordo com Antonio Negri (2016), em torno de 1968, e fundamentalmente pelas leituras singulares de Gilles Deleuze e de Alexandre Matheron, uma nova interpretação ontológica de Espinosa apareceu. Foi justamente no lastro desta inovação interpretativa que o pensamento espinosista se alastrou não só pela Europa, mas também pelos Estados Unidos e pela América Latina. Se há uma espécie de reversão na leitura tradicional, um dos elementos que se altera nesta leitura realizada por Deleuze e Matheron diz respeito ao conceito de imanência. Segundo indica Negri, a "nova interpretação destruía a ideia de imanência como profundidade; contrariamente a isso, ela dava da imanência uma leitura de superfície" (2016, p. 228), o que "constituía a imanência como horizonte da possibilidade" (2016, p. 228) mais do que de essência. Se toda "substância é necessariamente infinita (Spinoza, 2015, p. 51), o que Deleuze indicava era que a imanência era infinita substância que produz ininterruptamente modos de expressão (Deleuze, 2017). Desde essa leitura, com a colocação da imanência sob um caráter superficial e expressivo, uma revisão de ordem estético-política se fazia também necessária. Sem transcendentais quaisquer, já que tudo é superfície expressiva, dissipam-se os transcendentais de governo - seja os da teoria aristotélica, seja os da hipótese hobbesiana da necessária hipóstase da autoridade. No lugar da gestão transcendental, aparece a democracia da multidão, ou o "absoluto autogoverno do conjunto das individualidades” (Negri, 2016, p. 228) que outra coisa não é se não a constituição do comum. Trata-se, portanto, da plena coligação entre a noção ontológica da imanência à noção política do comum. E, mais uma vez, a partir da superficialidade 
da imanência, já não haveria mais espaço para uma divindade transcendente ou para um reino transcendental dos fins: já não haveria mais espaço para nada que se colocasse "fora da experiência criativa do existente" (Negri, 2016, p. 229). Se a imanência é o que há, e se nisso que há reside também um caráter de eternidade, eterno era o caminho da experiência criativa: uma espécie de levante genealógico contra toda teleologia. Forja-se, portanto, a partir da superfície imanente, a conjunção entre o elemento político do comum e o elemento estético da criação, pois doravante a matéria, com sua "tonalidade cambiante e sempre aberta" seria entendida como "o tecido das transformações do mundo" (Negri, 2016, p. 229). A imanência era a matéria metamórfica do que há: um plano comum de criação insuprimível da existência.

No curso ministrado no Centre Universitaire Expérimental de Vincennes, entre 1980 e 1981, dedicado a acompanhar o pensamento de Espinosa, Deleuze lembra que a filosofia, ao menos até o final do século XVII, fala o tempo todo de Deus, e que com Espinosa certamente não é diferente. Mas Deleuze também lembra que aquilo a que Espinosa chama de Deus, logo no primeiro livro da Ética, vai ser a coisa mais estranha do mundo: trata-se de um conceito que reúne em si o conjunto de todas as suas possibilidades. Dizia Espinosa: "Por Deus entendo o ente absolutamente infinito, isto é, a substância que consiste em infinitos atributos, cada um dos quais exprime uma essência eterna e infinita" (Spinoza, 2015, p. 45). Era um Deus desvirtuado da transcendência - e, portanto, da possibilidade de julgamento hierárquico - que ali aparecia. Com Espinosa, para além de qualquer transcendência ou possibilidade de julgamento, Deus está no mundo e o mundo está em Deus (Deleuze, 2008). Deus é substância, e por substância Espinosa entende "aquilo que é em si e é concebido por si, isto é, aquilo cujo conceito não precisa do conceito de outra coisa a partir do qual deva ser formado" (Spinoza, 2015, p. 45), pois "a substância absolutamente infinita é indivisível" (Spinoza, 2015, p. 65).

É este estranho conceito que permitirá que em Espinosa tudo se passe como em um plano fixo: um plano que podemos chamar de imanência. Todavia, tal plano fixo não será um plano de imobilidade, já que é nele exatamente que todas as coisas que existem vão se mover. Pode-se dizer que para Espinosa só o que conta é o movimento das coisas sobre este plano fixo - este plano fixo no qual todos os modos de vida acontecem e ao qual doravante poderemos chamar de plano de imanência.

Mas como começar uma ontologia onde o ser está literalmente em todas as partes? Talvez o grande jogo estratégico-teórico de Espinosa se localize junto ao fato de que essa ontologia não começa exatamente por Deus. Ao contrário, a ficção ontológica engendrada por Espinosa tem início pelos elementos constituintes da substância - ou pelos atributos, que são exatamente as classes de expressão da substância. É assim que, para o filósofo holandês, é a univocidade que depende da multiplicidade do ser - e não a multiplicidade do ser que depende do uno: em outros termos, é a substância que depende dos modos, e não os modos que dependem da substância.

Assim, "o plano de imanência não precede o que vem povoá-lo ou preenchê-lo, mas é construído e remanejado na experiência” (Zourabichvili, 2016, p. 87): o plano de imanência é, portanto, um plano de acontecimentos que não cessa de efervescer. O essencial nesta tese é que ela carrega em si a afirmação plena e radical da imanência - mas jamais da identidade ou da igualdade. Com efeito, pode-se se dizer que, com Espinosa e com Deleuze, a imanência é o "diferenciante das diferenças" (Zourabichvili, 2016, p. 108): o plano no qual a diferença se constitui e acontece. 
Se nomeamos comum à aposta política que fazemos, talvez seja importante lembrar que, com esses extratos ontológicos, o comum "não tem aqui mais o sentido de uma identidade genérica, mas de uma comunicação transversal e sem hierarquia entre seres que apenas diferem” (Zourabichvili, 2016, p. 108). Assim, “o um da univocidade condiciona a afirmação do múltiplo em sua irredutibilidade” (Zourabichvili, 2016, p. 109). Quase sob uma fórmula, podemos dizer que a imanência é ontologicamente uma e formalmente múltipla.

Sob a ficção espinosista, tornamo-nos pacotes de relações (Deleuze, 2008), e a individualidade é apenas a realização de uma maneira de ser que efetiva o plano de imanência - o que necessariamente interroga as implicações advindas das relações entre indivíduo e sociedade que a Psicologia Social tradicionalmente majoritária construiu. Uma superfície com a qual entramos em contato apenas a partir destas pequenas dobras - as construções subjetivas, portanto, como territorializações que nos colocam problemas à medida que se forjam.

É a partir dessa noção de imanência, em que todas as coisas se dão nessa estranha unidade não totalitária, que pensaremos a ontologia. A imanência, enfim, como aquilo que existe em si e por si, porém também como aquilo que transparece em tudo que existe, se conecta e se movimenta - e que retira, portanto, as condições teóricas para que a individualidade e a interioridade involucradas se efetivem: o dentro torna-se tão somente uma dobra do fora, a singularidade tão somente um modo de concretização da imanência e do comum. Eis aqui o aparecimento da utilidade da imanência espinosista para nossa empreitada de campo e o legado que gostaríamos de extrair, com Espinosa, para a Psicologia Social.

\section{Nietzsche: a genealogia, a força e o campo de batalha}

Dados os primeiros passos em nossa construção ontológica, seguiremos recolhendo os fragmentos modernos que nos ajudam a forjar algumas bases para o nosso esforço de composição ontológica para uma certa Psicologia Social a qual começamos a defender a partir da construção da noção de ontologia do comum.

É com Nietzsche que pensaremos uma espécie de povoamento do plano de imanência espinosista, e o faremos tendo como centralidade o conceito de força. Se desde Espinosa a imanência é o plano comum onde tudo se dá - onde tudo é potência de expressão e nada é transcendência - as forças seriam justamente aquilo que constitui este plano, inscrevendose nele e produzindo-o em suas mais diversas modulações.

Sob a acepção nietzschiana, tudo que há é força: força debatendo-se com e contra outra força. Assim, a estranha essência de uma força seria determinada pelo modo como ela se relaciona com outra. Essa relação entre forças nos desloca para o jogo hierárquico deste modo de relação - uma força dominante e outra dominada, uma vontade obedecida e outra vontade obediente, um vir-a-ser e um perecer, por fim, uma força ativa e outra reativa.

A partir deste estatuto ontológico da força, Nietzsche anuncia, assim como Espinosa, o corpo como "um fenômeno múltiplo, sendo composto por uma pluralidade de forças irredutíveis” (Deleuze, 1971, p. 21). Logo, pensaremos o corpo não só em seu sentido físico e biológico, mas como conceito amplo que abarca toda e qualquer força que entre em relação com outra - o corpo, portanto, como químico, biológico, social e político, como aquilo que 
há de mais surpreendente, "um ser mais poderoso, um sábio desconhecido, que se chama si. Ele habita teu corpo, ele é teu corpo" (Nietzsche, 1983, p. 51). Eis uma manobra de extrema importância para a Psicologia Social: retirar o eu de cena e colocar o si como o objeto de análise e de intervenção - o si que não é outra coisa se não o campo do encontro e da consistência das forças, quebrando toda e qualquer possibilidade de separação pura e cristalina, tão cara a tradições distintas da Psicologia Social, entre um dentro e um fora da subjetividade.

Pensaremos o sentido de algo como a relação da coisa com a força que dela se apodera, enquanto que o valor desse mesmo algo é aquilo que se expressa a partir da hierarquia de forças que põe em evidência a complexidade dos fenômenos. Ao nos referirmos a essa analítica da hierarquia das forças e a essa história dos valores, adentramos o campo do que Nietzsche e alguns de seus intercessores chamarão de genealogia. Esta espécie de método opera a análise das condições de possibilidade para a irrupção de determinado acontecimento.

Em Nietzsche, a genealogia e a história, Foucault (1979a) defende que a genealogia se opõe necessariamente à pesquisa histórica dedicada a busca de origens ou de essências exatas e imutáveis. Ao modo mais nietzschiano possível, o pensador francês diz que a genealogia pesquisa a emergência, e que a "emergência se produz sempre em um determinado estado das forças" (Foucault, 1979b, p. 23). Para ele, a emergência seria, portanto, "a entrada em cena das forças" (Foucault, 1979b, p. 24).

Tal perspectiva histórico-metodológica certamente traz consigo certa direção anterior - uma direção a qual gostaríamos de nomear como ontológica. Porque aquilo que Nietzsche nomeia como história é um jogo de forças em eterna disputa: irrupção, descontinuidade, vitórias e derrotas. Tal indicação faz com que a história - "com suas intensidades, seus desfalecimentos, seus furores secretos, suas grandes agitações febris como suas síncopes" (Foucault, 1979b, p. 20), seja o próprio corpo do devir. Sob a acepção nietzschiana as "forças que se encontram em jogo na história não obedecem nem a uma destinação, nem a uma mecânica, mas ao acaso da luta” (Foucault, 1979b, p. 28). A história, portanto, é jogo de forças que se dá sempre e inevitavelmente como expressões da e na imanência.

Logo, no encontro entre a imanência e a genealogia, trata-se das vitórias e derrotas das forças. É “a partir dessa perspectiva genealógica que o social deixa de ser considerado uma evidência para ser tomado como um objeto essencialmente construído" (Silva, 2004). Eis o que queríamos extrair do eterno retorno nietzschiano para nossa empreitada de campo: pensá-lo como um movimento de afirmação radical da vida e de suas forças. Assim, a Psicologia Social com a qual gostaríamos de trabalhar - já insinuada sob o plano de imanência espinosista - agora adquire a presença ontológica de forças que não cessam de jogar e diferir: um esforço analítico e constitutivo de um mundo sem transcendência, mundo que não cessa de acontecer na plena efetividade da diferença - da repetição da diferença, do eterno retorno da diferença em um único e mesmo plano. Eis, enfim, os fragmentos para o esboço de uma ontologia do comum no campo da Psicologia Social.

\section{À guisa de fechamento e abertura}

A trajetória da Psicologia Social é absolutamente tortuosa: desde o século XIX, tal área de saber se fez sob movimentos de enfrentamentos teórico-políticos praticamente 
ininterruptos. Não são poucos os pesquisadores desta história que indicam a impossibilidade de unidade na Psicologia Social (Bernardes, 1998; Farr, 2013; Lima, 2009; Spink \& Spink, 2006). Entende-se que tomar como ponto de partida aquilo que estamos chamando de ontologias do comum nos abre caminho para uma Psicologia Social que não se encaixa nas vertentes mais conhecidas de sua história - estas sempre múltiplas, motivo pelo qual chamamos de tortuoso o seu percurso. Certamente, nossa aposta não se encontra próxima a Psicologia Social Psicológica, nem a Psicologia Social Sociológica (Farr, 2013), por colocar em questão justamente a maneira dicotômica e essencialista como são tratadas as categorias de indivíduo e sociedade. Ademais, o movimento consequente de nosso empreendimento ontológico de embaralhamento e desnaturalização das noções de indivíduo e sociedade também se afasta da chamada Psicologia Social Crítica - o movimento latino americano de contraposição às práticas cognitivistas em Psicologia Social que, aliadas ao marxismo, pautam uma prática e uma teoria psicológica que se faça junto aos movimentos sociais, tendo em vista a transformação revolucionária da sociedade - por colocar em análise um vetor institucionalizante desta perspectiva, que desemboca ainda em essencialismos e teleologias, tais como "o social”, “o proletário”, "a revolução”. Leva-se da Psicologia Social Crítica a necessidade e o compromisso com a transformação social, mas, tendo em vista e ao fundo as ontologias do comum, trazemos essa necessidade de transformação próxima a uma ética e a uma estética, em um constante e ininterrupto questionamento da própria prática que só se faz em jogos simultaneamente imanentes e genealógicos: o mundo como máquina de expressão comum das forças.

A intenção do presente artigo, portanto, jamais foi - até porque seria impossível fazê-lo - encontrar o ponto derradeiro desta trajetória. $\mathrm{O}$ artigo que ora finda também não se prestou a fazer aparecerem novidades conceituais - já que foi com as produções bastante conhecidas de Nietzsche e de Espinosa que ele teve tecidos seus argumentos e posições. Mais do que tudo, aquilo a que este trabalho se deu foi apresentar algumas indicações para que aquilo que chamamos de ontologias do comum - um plano de imanência absolutamente diferencial - apresente-se junto a outros tantos elementos legítimos deste campo multifacetado e caleidoscópico que é a Psicologia Social.

\section{Referências}

Bernardes, J. S. (1998). História. In M. N. Strey et al. (Orgs.), Psicologia Social Contemporânea: livro-texto (pp. 19-35). Petrópolis, RJ: Vozes.

Bove, L. (2010). Espinosa e a Psicologia Social: ensaios de ontologia política e antropogênese. Belo Horizonte: Autêntica.

Canguilhem, G. (1973). O que é a Psicologia? Tempo Brasileiro, 30/31(109), 104-123.

Costa, F. A. \& Prado, M. A. M. (2016). Crítica, política e Psicologia Social: a mudança social e o lugar da ação intelectual na luta política. Estudos de Psicologia, 21(2), $216-227$.

Deleuze, G. (1971). Nietzsche e a Filosofia. Rio de Janeiro: Editora Rio.

Deleuze, G. (1997). Platão, os gregos. In Crítica e clínica (pp. pp. 154-155). São Paulo: Ed. 34.

Deleuze, G. (2008). En medio de Spinoza. Buenos Aires: Cactus.

Deleuze, G. (2017). Espinosa e o problema da expressão. São Paulo: Editora 34.

Deleuze, G. \& Guattari, F. (1992). O que é a Filosofia? São Paulo: Ed. 34.

Farr, R. (2013). As raízes da Psicologia Social moderna. Petrópolis, RJ: Vozes. 
Foucault, M. (1979a). Genealogia e o poder. In Microfísica do poder (pp. 167-178). Rio de Janeiro: Edições Graal.

Foucault, M. (1979b). Nietzsche, a genealogia e a verdade. In Microfisica do poder (pp. 15-38). Rio de Janeiro: Edições Graal.

Foucault, M. (2014). Aulas sobre a vontade de saber: curso no Collège de France (1970-1971). São Paulo: Martins Fontes.

Gonçalves, M. A. \& Portugal, F. T. (2016). Análise histórica da Psicologia Social comunitária no Brasil. Psicologia E̊ Sociedade, 28(3), 562-571.

Huining, S. M. \& Scisleski, A. C. C. (2018). Ressonâncias de uma epistemologia foucaultiana em Psicologia Social. Psicologia E Sociedade, 30, http://dx.doi.org/10.1590/18070310/2018v30170632.

Ilbañez, T. (1994). Psicologia Social Construccionista. Mexico: Universidad de Guadalajara.

Jacó-Vilela, A. M., Degani-Carneiro, F., \& Oliveira, D. M. O. (2016). A formação da Psicologia Social como campo científico no Brasil. Psicologia \& Sociedade, 28(3), 526-536.

Lima, R. S. (2009). Psicologia Social. In C. D. Tourinho \& R. S. Lima (Orgs.), Estudos em Psicologia: uma Introdução (pp. 161-180). Niterói, RJ: Proclama.

Martín-Baró, I. (2017). Crítica e libertação na psicologia: estudos psicossociais. Petrópolis, RJ: Vozes.

Negri, A. (2016) Espinosa subversivo e outros escritos. Belo Horizonte: Autêntica.

Nietzsche, F. (1983). Assim falou Zaratustra. Rio de Janeiro: Civilização Brasileira.

Silva, R. N. (2004). Notas para uma genealogia da Psicologia Social. Psicologia \& Sociedade, $16(2), 12-19$.

Spink, M. J. P. \& Spink, K. S. (2005) A psicologia social na atualidade. In A. M. Jacó-Vilela, A. A. L. Ferreira, \& F. T. Portugal (Orgs.), História da Psicologia: rumos e percursos (pp. 565-585). Rio de Janeiro: Nau.

Spinoza, B. (2015). Ética. São Paulo: Editora da Universidade de São Paulo.

Zourabichvili, F. (2016). Deleuze: uma filosofia do acontecimento. São Paulo: Ed. 34.

\section{CLARA URZEDO ROCHA MOTTA \\ http://orcid.org/O000-0001-7065-9765}

Estudante de graduação em Psicologia da Universidade Federal Fluminense, RJ.

Endereço: Rua General Andrade Neves, n. 313, apto. 202, São Domingos, Niterói, RJ.

E-mail: clara.urm@gmail.com

\section{DANICHI HAUSEN MIZOGUCHI}

http://orcid.org/0000-0002-7147-3521

Psicólogo formado pela Universidade Federal do Rio Grande do Sul, mestre e doutor em Psicologia pela Universidade Federal Fluminense. Professor do Departamento e do Programa de Pós-graduação em Psicologia da Universidade Federal Fluminense.

E-mail: danichihm@,hotmail.com 
Submissão: 28/11/2017

Histórico

Revisão: 06/02/2019

Aceite: 08/03/2019

Concepção: CURM; DHM.

Coleta de dados: CURM; DHM.

Análise de dados: CURM; DHM.

Contribuição dos autores

Elaboração do manuscrito: Elaboração do manuscrito: CURM; DHM.

Crítica/revisões de conteúdo intelectual importante: CURM; DHM.

Aprovação do manuscrito: CURM; DHM.

Financiamento

Não houve

Consentimento de uso de imagem

Não se aplica 